\title{
Long Non-Coding RNA MALAT1 Gene Polymorphism is Associated with Disease-Free Survival in Bladder Cancer Patients
}

\author{
Andrii Volkogon*, Olena Kolnoguz, Viktoriia Harbuzova, Alexander Ataman
}

\begin{abstract}
The objective of the research was to study the possible association between MALAT1 gene rs3200401 polymorphism and the survival of patients with bladder cancer and clinicopathological characteristics in bladder cancer.

Materials and Methods. The venous blood of 141 patients with transitional cell carcinoma of the urinary bladder was used for study. Genotyping of MALAT1 gene rs3200401 polymorphism was performed by real-time polymerase chain reaction using the 7500 Fast Real-Time PCR System (Applied Biosystems, Foster City, USA) and Taq-Man Assays (TaqManOSNP Assay C_3246069_10). Statistical analysis was performed using the SPSS software package (version 17.0). The Kaplan-Meier estimator and Cox regression were used to check the possible association between MALAT1 rs3200401-genotypes and the age of transitional cell carcinoma of the urinary bladder onset. $\mathrm{P}$ values $<0.05$ were considered as statistically significant.

Results. The obtained results revealed that hemoglobin concentration was lower in patients with transitional cell carcinoma of the urinary bladder and rs3200401TT-genotype than in patients with rs3200401CC-genotype $(p=0.024)$. Herewith, fasting glucose, creatinine concentration, and tumor width were significantly higher in patients with transitional cell carcinoma of the urinary bladder and rs3200401TT-genotype as compared to rs3200401CC-genotype carriers $(p=0.036, p=0.039, p=0.028$, respectively). The results of survival analysis demonstrated that transitional cell carcinoma of the urinary bladder occurred much later in persons with rs3200401TT-genotype as compared to rs3200401C-allele carriers (log rank $p=0.016$ ), and the risk of transitional cell carcinoma of the urinary bladder onset was lower in individuals with rs3200401TT than in major rs3200401C C-allele carriers (hazard ratio $=0.413 ; p=0.047$ ).

Conclusions. Rs3200401 polymorphism of MALAT1 gene is associated with disease-free survival in Ukrainian patients with transitional cell carcinoma of the urinary bladder. Transitional cell carcinoma of the urinary bladder occurs later in persons with rs3200401TT-genotype than in individuals with rs3200401CC- and rs3200401CTgenotypes.
\end{abstract}

Keywords

MALAT1; IncRNA; bladder cancer; gene polymorphism; survival

Sumy State University, Ukraine

*Corresponding author: volkogon_andrei@ukr.net

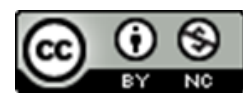

Copyright @Andrii Volkogon, Olena Kolnoguz, Viktoriia Harbuzova, Alexander Ataman, 2020

\section{Problem statement and analysis of the latest research}

Metastasis-associated lung adenocarcinoma transcript 1 (MALAT1) also known as non-coding nuclear- enriched abundant transcript 2 (NEAT2) is highly conserved long non-coding RNA (lncRNA) that is actively expressed in various human cells and tissues (kidney, brain, heart, thyroid gland, adrenal glands, skeletal muscles, ovaries, intestines, lungs, 


\section{Long Non-Coding RNA MALAT1 Gene Polymorphism is Associated with Disease-Free Survival}

in Bladder Cancer Patients - 2/7

liver, prostate, etc.) [1]. The MALAT1 gene transcript was first described in 1997 as an alpha transcript in patients with multiple endocrine neoplasia type 1 (MEN-1) [2]. In 2003, MALAT1 was identified as a transcript associated with metastasis in patients with early-stage non-small cell lung cancer [3]. Today, the main MALAT1 function is thought to be the regulation of metastasis-related genes expression [4]. In addition, its important role in cellular processes such as alternative splicing, nuclear organization, and epigenetic modulation of gene expression has been proven [5].

In 2012, MALAT1 overexpression in bladder cancer (BC) cells was revealed by Ying et al. [6]. Researchers also showed that level of MALAT1 production in primary BC tumors of patients with metastases was significantly higher as compared to tumors of patients without metastases. Along with this, Xie et al. have recently demonstrated that lncRNA MALAT1 suppresses apoptosis of malignant bladder cells and promotes their invasion through miR-125b inactivation [7].

Li et al. have established the link between MALAT1 expression level on the one hand and the degree of $\mathrm{BC}$ cell differentiation, the stage of cancer and the presence of distant metastases on the other hand [8]. In addition, researchers have shown that overall survival in BC patients with high MALAT1 expression was much lower than in BC patients with low MALAT1 production. Zhan el. revealed that excessive MALAT1 expression reduced the time of recurrence development in post-operated BC patients [9]. However, no relationship between MALAT1 expression level and morphological characteristics of malignant bladder tumor has been found.

Today, there are several studies on the association between MALAT1 genetic polymorphism and malignant tumors emergence and development [10, 11]. However, there are no studies devoted to analysis of association between MALAT1 gene polymorphic sites and $\mathrm{BC}$ risk, different $\mathrm{BC}$ tumor characteristics, and $\mathrm{BC}$ patient survival.

The objective of the research was to study the possible association between MALAT1 gene rs3200401 polymorphism and the survival of BC patients and clinicopathological characteristics in BC.

\section{Materials and Methods}

The venous blood of 141 patients with transitional cell carcinoma of the urinary bladder (TCCUB) (mean age $[ \pm \mathrm{SD}] 67.60 \pm 12.12$ years) was used for study. All patients were treated at Sumy Regional Clinical Oncology Hospital from 2005 to 2016. The final morphological diagnosis of TCCUB was made in accordance with the European Association of Urology (EAU) Guidelines (2016) $[12,13]$. All patients had stage II cancer according to the Tumour-Node-Metastasis (TNM) classification of malignant tumors ( $8^{\text {th }}$ edition, 2017) [14], which was established by histological examination or Magnetic Resonance Imaging (MRI) results. Persons with hereditary pathologies, diseases of unknown etiology, and tumors of other localization were excluded from the study.

The study was conducted in compliance with the Council of Europe Convention for the Protection of Human Rights and Biomedicine, the Declaration of Helsinki, and the Order of the Ministry of Health of Ukraine No 690 (23.09.2009). All participants signed the informed consent for genetic testing. The study protocol was approved by the Ethic Committee of the Medical Institute of Sumy State University (No 3/05.12.11).

Whole venous blood was collected into $2.7 \mathrm{ml}$ Monovette tubes with addition of EDTA (Sarstedt, Germany). DNA was extracted from venous blood leukocytes using commercial Thermo Scientific GeneJET Whole Blood Genomic DNA Purification Mini Kit (USA).

Genotyping of MALAT1 gene rs3200401 polymorphism was performed by a real-time polymerase chain reaction (Real-Time PCR) using 7500 Fast Real-Time PCR System (Applied Biosystems, Foster City, USA) and Taq-Man Assays (TaqMan@SNP Assay C_3246069_10). The amplification reaction consisted of 50 cycles: initial denaturation $-95^{\circ} \mathrm{C}$ $(20 \mathrm{~s})$, denaturation $-95^{\circ} \mathrm{C}(30 \mathrm{~s})$ hybridization and elongation $-60.0^{\circ} \mathrm{C}(30 \mathrm{~s})$. Analysis of obtained data was performed using the 7500 Fast Real-Time 
Table 1. Clinicopathological characteristics of TCCUB patients with different MALAT1 rs3200401 genotypes.

\begin{tabular}{|c|c|c|c|c|}
\hline \multirow[b]{2}{*}{ Parameter } & \multicolumn{3}{|c|}{ Genotype } & \multirow[b]{2}{*}{$\mathrm{p}$} \\
\hline & $\begin{array}{c}\mathrm{CC} \\
(\mathrm{n}=106)\end{array}$ & $\begin{array}{c}\text { CT } \\
(n=29)\end{array}$ & $\begin{array}{c}\text { TT } \\
(n=6)\end{array}$ & \\
\hline \multicolumn{5}{|c|}{ Blood analysis } \\
\hline $\mathrm{Hb},(\mathrm{g} / \mathrm{l})$ & $131.1 \pm 21.9$ & $124.0 \pm 21.5$ & $106.3 \pm 23.9$ & 0.014 \\
\hline WBC, $\left(10^{9} / 1\right)$ & $7.2 \pm 2.4$ & $6.2 \pm 1.9$ & $8.2 \pm 1.9$ & 0.056 \\
\hline $\mathrm{ESR},(\mathrm{mm} / \mathrm{h})$ & $14.7 \pm 11.2$ & $20.0 \pm 15.7$ & $23.3 \pm 30.6$ & 0.075 \\
\hline Fasting glucose, $(\mathrm{mmol} / \mathrm{l})$ & $5.4 \pm 1.5$ & $5.5 \pm 1.5$ & $7.1 \pm 2.3$ & 0.043 \\
\hline Creatinine, $(\mu \mathrm{mol} / \mathrm{l})$ & $83.8 \pm 18.5$ & $90.0 \pm 20.4$ & $104.5 \pm 33.8$ & 0.022 \\
\hline \multicolumn{5}{|c|}{ Tumor morphology } \\
\hline Tumor length, (sm) & $3.2 \pm 1.1$ & $3.4 \pm 1.2$ & $3.5 \pm 1.5$ & 0.780 \\
\hline Tumor width, (sm) & $2.9 \pm 1.1$ & $3.1 \pm 1.2$ & $4.2 \pm 1.7$ & 0.027 \\
\hline Tumor height, (sm) & $3.3 \pm 1.0$ & $3.2 \pm 1.0$ & $3.9 \pm 1.2$ & 0.283 \\
\hline Tumor volume, $\left(\mathrm{sm}^{3}\right)$ & $38.2 \pm 36.7$ & $42.8 \pm 34.3$ & $74.4 \pm 72.4$ & 0.076 \\
\hline
\end{tabular}

Notes: $\mathrm{Hb}$ - hemoglobin; WBC - white blood cells; ESR - erythrocyte sedimentation rate; $\mathrm{n}$ - number of patients.

PCR Software.

Statistical analysis was performed using the SPSS software package (version 17.0). Continuous data are presented as mean $\pm \mathrm{SD}$; nominal data are presented as quantitative and percent values. All continuous variables were normally distributed (the Shapiro-Wilk test). To check the deviation of MALAT1 rs3200401-genotypes distribution from the Hardy-Weinberg equilibrium, the Pearson's $\chi^{2}$ criterion was used. The significance of mean value differences in groups with different rs3200401-genotypes was determined using the one-way analysis of variance (ANOVA), followed by the Bonferroni correction. The Kaplan-Meier estimator and Cox regression were used to check the possible association between MALAT1 rs3200401genotypes and the age of TCCUB onset. Cox regression was performed under dominant, superdominant, and recessive models of inheritance, both without adjustment, and after adjustment for age, gender, body mass index, metastases, smoking habits, and alcohol abuse. All tests were two-sided, $p$ values $<0.05$ were considered as statistically significant.

\section{Results}

MALAT1 gene rs3200401 polymorphism genotyping revealed that the ratio of CC-homozygotes, $\mathrm{CT}$ heterozygotes and TT-homozygotes in TCCUB patients was $75.2 \%, 20.6 \%$ and $4.3 \%$, respectively. The distribution mentioned above (minor T-allele frequency - 0.15) did not deviate from the HardyWeinberg equilibrium $(\mathrm{p}=0.143)$.

The results analyzing the association between of MALAT1 gene rs3200401 polymorphic site and some laboratory parameters in TCCUB patients and tumor morphological characteristics are presented in Table 1. Significant association was established for hemoglobin ( $\mathrm{p}=0.014)$, fasting glucose $(p=0.043)$, creatinine $(p=0.022)$, and tumor width $(\mathrm{p}=0.027)$. Analysis using the Bonferroni correction showed that hemoglobin concentration was significantly lower in persons with TT-genotype than in individuals with CC-genotype ( $p=0.024)$; herewith, fasting glucose, creatinine concentration, and tumor width were significantly higher in TTCUB patients with TT-genotype as compared to CC-genotype carriers $(\mathrm{p}=0.036$, $\mathrm{p}=0.039, \mathrm{p}=0.028$, respectively).

The next step of our study was to analyze the 


\section{Long Non-Coding RNA MALAT1 Gene Polymorphism is Associated with Disease-Free Survival \\ in Bladder Cancer Patients - 4/7}

possible association between MALAT1 gene rs3200401 polymorphism and the age of TCCUB onset. The mean age of TCCUB onset depending on rs3200401-genotypes is shown in Table 2. Fig. 1 shows the Kaplan-Meier curve for cancer-free survival analysis depending on MALAT1 rs3200401genotypes according to the additive model. It is demonstrated that TCCUB occurred much later in persons with TT-genotype as compared to carriers of CC- and CT-genotypes (log rank $\mathrm{p}=0.016)$.

Table 2. BC-free survival analysis depending on MALAT1 rs3200401 genotypes.

\begin{tabular}{l|ccccc}
\hline $\begin{array}{l}\text { Geno- } \\
\text { type }\end{array}$ & $\mathrm{n}$ & $\begin{array}{c}\text { Mean } \\
\text { age }\end{array}$ & SE & $95 \% \mathrm{CI}$ & $\begin{array}{c}\text { log } \\
\text { rank } \\
\mathrm{p}\end{array}$ \\
\hline $\mathrm{CC}$ & 106 & 61.8 & 1.3 & $59.2-64.4$ & \\
$\mathrm{CT}$ & 29 & 66.1 & 1.7 & $62.9-69.4$ & 0.016 \\
$\mathrm{TT}$ & 6 & 77.3 & 3.4 & $70.7-84.0$ & \\
\hline
\end{tabular}

Notes: : SD - standard error; $95 \% \mathrm{CI}-95 \%$ confidence interval.

The results of Cox regression analysis are shown in Table 3. TCCUB risk was found to be significantly lower in individuals with TT genotype than in major $\mathrm{C}$-allele carriers (hazard ratio $(\mathrm{HR})=0.343$; $p=0.012$ ). The results were maintained after adjusting for age, sex, body mass index, metastases, smoking habits, and alcohol abuse $(\mathrm{HR}=0.413$; $\mathrm{p}=0.047)$.

\section{Discussion}

MALAT1 gene is located on chromosome 11 (11q13.1), contains 8, 708 base pairs and includes 2 exons [9]. Today, 5, 730 single-nucleotide polymorphisms (SNP) of MALAT1 gene are known [15]. One of the most studied in the context of cancer development is rs3200401 locus.

The essence of rs3200401 SNP of MALAT1 gene is the replacement of cytosine to thymine at 65504361 position of chromosome 11. Experimental results have shown that such nucleotide substitution causes the increase in MALAT1 molecule minimum free energy, which, in turn, alters its spatial structure and impairs its interaction with serine/arginine-rich splicing factor SC35 [11]. The impairment of interaction between MALAT1 and SC35 results in the inhibition of pre-mRNA splicing and the expression of genes involved in tumor metastasis.

The results of our study showed that MALAT1 gene rs3200401 polymorphic site is associated with disease-free survival in patients with TCCUB. BC has been shown to occur much later in individuals with TT-genotype as compared to major C-allele carriers. Similar data were obtained by Wang et al. [11]. Researchers have shown that lung cancer patients with rs3200401CT- and rs3200401TT-genotypes had significantly longer median survival time than patients with $\mathrm{CC}$-genotype. Along with this, Peng et al. have revealed that women with rs3200401CT-genotype had significantly lower risk of breast cancer development as compared to CC-homozygotes [10].

In addition, our study found that rs3200401TT genotype was associated with low hemoglobin content and high creatinine and fasting glucose concentrations as compared to rs3200401CC genotype. There may be molecular mechanism which can explained such negative effect of rs3200401T-allele. At least, Wang et al. have shown that, in contrast to protective effect on malignant tumor development, the rs3200401T- allele is a part of haplotype that increases coronary heart disease risk in Chinese population [16].

Moreover, we found that tumor width was significantly larger in rs3200401TT-heterozygotes than in rs3200401CC-homozygote. This may be the result of small amount of data being analyzed. Herewith, no relation between rs3200401 locus and length, height, and total volume of tumor has been detected. Thus, more individuals should be included in the study in order to make final conclusion about association between rs3200401 SNP and morphological characteristics of TCCUB tumors.

\section{Conclusions}

This is the first study investigating the association between MALAT1 gene rs3200401 SNP and diseasefree survival of $\mathrm{BC}$ patients and clinicopathological 


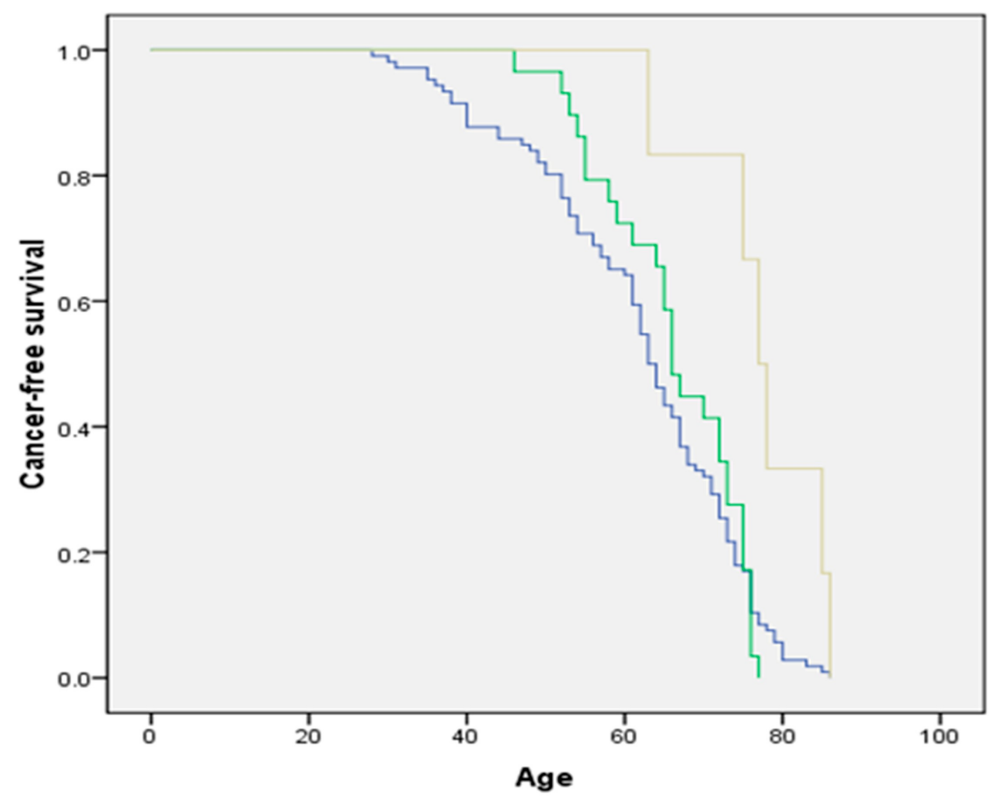

MALAT1

$\rightarrow \mathrm{ICC}$

TT

Figure 1. Kaplan-Meier curve for BC-free survival analysis depending on MALAT1 rs3200401 genotype.

Table 3. Analysis of association between MALAT1 rs3200401genotypic and TCCUB-free survival.

\begin{tabular}{l|ccc|crc}
\hline \multirow{2}{*}{ Model } & \multicolumn{3}{|c|}{ Univariate analysis } & \multicolumn{3}{c}{ Multivariate analysis } \\
& HR & $95 \%$ CI & P & HR & $95 \%$ CI & P \\
\hline TT+CT vs CC & 0.723 & $0.492-1.061$ & 0.097 & 0.782 & $0.521-1.173$ & 0.235 \\
CT vs TT+CC & 1.003 & $0.663-1.519$ & 0.987 & 1.003 & $0.655-1.535$ & 0.991 \\
TT vs CT+CC & 0.343 & $0.148-0.793$ & 0.012 & 0.413 & $0.172-0.987$ & 0.047 \\
\hline
\end{tabular}

characteristics in BC. Rs3200401 polymorphism of MALATl gene is associated with disease-free survival in Ukrainian patients with TCCUB. TCCUB occurs later in persons with rs3200401TTgenotype than in individuals with rs3200401CCand rs3200401CT-genotypes.

\section{Conflict of Interest}

The authors stated no conflict of interest.

\section{Financial Disclosure}

The authors declared no financial support.

\section{References}

[1] Ulitsky I, Shkumatava A, Jan $\mathrm{CH}$ et al. Conserved function of lincRNAs in vertebrate embryonic development despite rapid sequence evolution. Cell. 2011; 147 (7): 1537-1550. DOI: https://doi.org/10.1016/j. cel1.2011.11.055

[PMid:22196729 PMCid:PMC3376356]

[2] Marx SJ. Molecular genetics of multiple endocrine neoplasia types 1 and 2 . Nat Rev Cancer. 2005; 5 (5): 367375. DOI: https: / / doi.org/10.1038/ nrc1610 [PMid:15864278]

[3] Ji P, Diederichs S, Wang W et al. MALAT1 , a novel noncoding RNA, and thymosin beta4 predict metastasis and survival in early-stage non-small cell lung cancer. Oncogene. 2003; 22 (39): 8031-8041. 
DOI: https://doi.org/10.1038/sj. onc. 1206928 [PMid:12970751]

[4] Sun Y, Ma L. New Insights into Long Non-Coding RNA MALAT1 in Cancer and Metastasis. Cancers. 2019; 11 (2): E216. DOI: https://doi.org/10.3390/ cancers 11020216

[PMid:30781877

PMCid:PMC6406606]

[5] Zhang X, Hamblin H, Yin KJ. The long noncoding RNA Malat1: Its physiological and pathophysiological functions. RNA Biol. 2017; 14 (12): 17051714. DOI: https://doi.org/10. $1080 / 15476286.2017 .1358347$

[PMid:28837398 PMCid:PMC5731810]

[6] Ying L, Chen Q, Wang Y et al. Upregulated MALAT-1 contributes to bladder cancer cell migration by inducing epithelial-tomesenchymal transition. Mol Biosyst. 2012; 8 (9): 2289-2294. DOI: https : / / doi . org/ $10.1039 / \mathrm{c} 2 \mathrm{mb} 25070$ e [PMid:22722759]

[7] Xie H, Liao X, Chen $Z$ et al. LncRNA MALAT1 Inhibits Apoptosis and Promotes Invasion by Antagonizing miR-125b in Bladder Cancer Cells. J Cancer. 2017; 8 (18): 3803-3811. DOI: https://doi .org/10. $7150 /$ jca.21228 [PMid:29151968 PMCid:PMC5688934]

[8] Li C, Cui Y, Liu LF et al. High Expression of Long Noncoding RNA MALAT1 Indicates a Poor Prognosis and Promotes Clinical Progression and Metastasis in Bladder Cancer. Clin Genitourin Cancer. 2017; 15 (5): 570576. DOI: https://doi.org/10.1016/ j.clgc.2017.05.001 [PMid:28648755]

[9] Zhan Y, Du L, Wang L et al. Expression signatures of exosomal long non-coding RNAs in urine serve as novel non-invasive biomarkers for diagnosis and recurrence prediction of bladder cancer. Mol Cancer. 2018; 17 (1): 142. DOI: https://doi.org/10.1186/ s12943-018-0893-y [PMid:30268126 PMCid:PMC6162963]

[10] Peng R, Luo C, Guo Q et al. Association analyses of genetic variants in long non-coding RNA MALAT1 with breast cancer susceptibility and mRNA expression of MALAT1 in Chinese Han population. Gene. 2018; 642: 241248. DOI: https://doi .org/10.1016/ j.gene.2017.11.013 [PMid:29146194]

[11] Wang JZ, Xiang JJ, Wu LG et al. A genetic variant in long non-coding RNA MALAT1 associated with survival outcome among patients with advanced lung adenocarcinoma: a survival cohort analysis. BMC Cancer. 2017; 17 (1): 167. DOI: https://doi. org/10.1186/s12885-017-3151-6 [PMid:28253859 PMCid:PMC5335789]

[12] Alfred Witjes J, Lebret T, Compé rat EM et al. Updated 2016 EAU Guidelines on Muscle-invasive and Metastatic Bladder Cancer. Eur Urol. 2017; 71 (3): 462-475. DOI: https://doi.org/10.1016/j. eururo.2016.06.020 [PMid:27375033]

[13] Babjuk M, Bö hle A, Burger M et al. EAU Guidelines on Non-Muscle-invasive Urothelial Carcinoma of the Bladder: Update 2016. Eur Urol. 2017; 71 (3): 447-461. DOI: https://doi.org/10.1016/j. eururo.2016.05.041 [PMid:27324428]

[14] Paner GP, Stadler WM, Hansel DE et al. Updates in the Eighth Edition of the TumorNode-Metastasis Staging Classification for Urologic Cancers. Eur Urol. 2018; 73 (4): 560-569. DOI: https://doi.org/ $10.1016 / j$.eururo.2017.12.018 [PMid:29325693]

[15] https: / / www.ncbi.nlm.nih.gov/ snp/?term=MALAT 1

[16] Wang G, Li Y, Peng Y et al. Association of polymorphisms in MALAT1 with risk of coronary atherosclerotic heart disease in 
Long Non-Coding RNA MALAT1 Gene Polymorphism is Associated with Disease-Free Survival

in Bladder Cancer Patients - 7/7

a Chinese population. Lipids Health Dis.

2018; 17 (1): 75. DOI: https://doi.

org/10.1186/s12944-018-0728-2

[PMid:29631611 PMCid:PMC5891990]

Received: $2020-02-23$

Revised: $2020-04-18$

Accepted: 2020-04-24 